\title{
AFM in the Conservation of Contemporary Paintings: The Case of the White Paintings of Julião Sarmento
}

\author{
A.I. Pereira ${ }^{1,2, \#, \text { M.J. Melo }}{ }^{* 1,2}$, P. Eaton ${ }^{3}$, S. Schäfer ${ }^{1}$, T. Learner ${ }^{4}$ \\ ${ }^{1}$ Departmento de Conservação e Restauro, Faculdade de Ciências e Tecnologia - Universidade Nova \\ de Lisboa, Quinta da Torre-Campus de Caparica, 2829-516 Caparica, Portugal, mjm@dq.fct.unl.pt \\ ${ }^{2}$-REQUIMTE, CQFB, Departamento de Química, FCT-UNL \\ ${ }^{3}$ REQUIMTE/Faculdade de Ciências da Universidade do Porto, R. Campo Alegre, 4169-007 Porto, \\ Portugal \\ ${ }^{4}$ Getty Conservation Institute, 1200 Getty Center Drive, Suite 700, Los Angeles, CA 90049-1684 \\ ${ }^{\#} \mathrm{PhD}$ Program in Conservation and Restoration, FCT-UNL
}

Vinyl paints have been used by Portuguese artists at least since the early sixties, and the performance of these paints regarding it's stability in the long term and, consequently adequate preventive measures and treatment is presently a subject of intense research and a major concern for conservators. Atomic Force Microscopy was been successfully used in former studies on the effects of photodegradation and of selected cleaning methods on the surface of vinyl paints. [1]

In this work we present the first results of an ongoing research on the materials used in the White Paintings of the Portuguese artist Julião Sarmento (b.1948). In the 90's Sarmento started to work on monochromatic white and textured backgrounds where black figures are depicted. His paints are homemade and consist of Cenógrafa ${ }^{\circledR}$ dry pigment mixed with an aqueous dispersion of a PVAc homopolymer, sold under the name Vulcano $\mathrm{V} 7^{\circledR}$. The white pigment is a mixture of lithopone with calcium carbonate and the black is a mixture of black iron oxide, a carbon-based black and calcium carbonate. All the materials were bought from the producer the Favrel Lisbonense, a Portuguese fine arts materials company. Information regarding the present state of conservation of these paintings frequently mentions yellowing of the paint and dirt deposition on the surface.

Three types of samples are being studied. 1) Laboratory reproductions where the paints are applied on glass micro slides and are artificially aged under a xenon irradiation. 2) A reproduction on canvas prepared by the artist in 2010, with the materials and techniques used in the 90s. 3) A white background on canvas, naturally aged as was kept at his studio since 1987-89.

In this paper we present the first findings on: 1) the evaluation of changes on the morphology of the paint surface due to aging and 2) comparison between laboratory paint samples aging and real paint samples. AFM images were obtained in the tapping mode on areas of 50x50 $\mathrm{m}$ and $10 \times 10 \mu \mathrm{m}$. Images of the artificially aged unpigmented homopolymer show a more irregular surface when compared to the unaged sample. Moreover the roughness value increases slightly. On the other hand, the surface of the black paint reproductions does not show relevant differences with aging which is also indicated by a minor variation of roughness values. Images of the white paint laboratory reproduction reveal a smoother surface which reflects a decrease of the $\mathrm{Ra}$ for the aged sample. Images obtained for the two white paints done by Sarmento show a very similar topography although the paint sample kept in the studio has lower Ra. Also, the surfaces of both of these samples show considerable differences compared to the laboratory reproductions. The results show that AFM imaging can be useful technique to study ageing moreover results correlate well with results obtained with other analytical techniques such as FTIR-ATR and GPC-SEC. Work in progress will also include evaluation of cleaning effects on the samples described. 


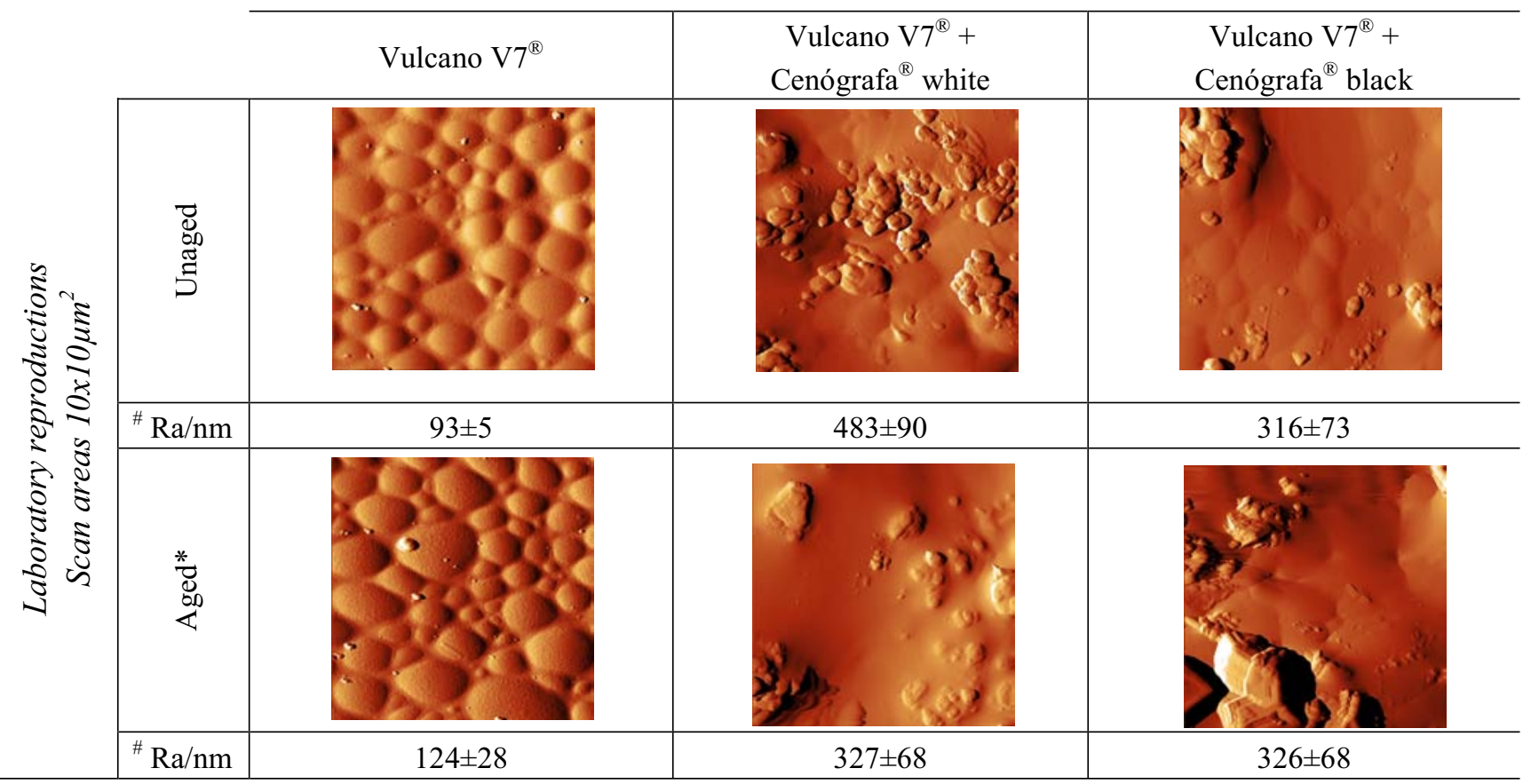

* Vulcano $\mathrm{V}^{\circledR}$, artificially aged for $1750 \mathrm{~h}$; Vulcano $\mathrm{V}^{\circledR}+$ pigment artificially aged for $4000 \mathrm{~h}$ ( Xenon irradiation ${ }^{\#} \mathrm{R} a$ was calculated as the average value from three to five scan areas of $10 \mathrm{x} 10 \mu \mathrm{m}^{2}$ for each sample.

TABLE 1. AFM amplitude images of laboratory paint reproductions unaged and artificially aged

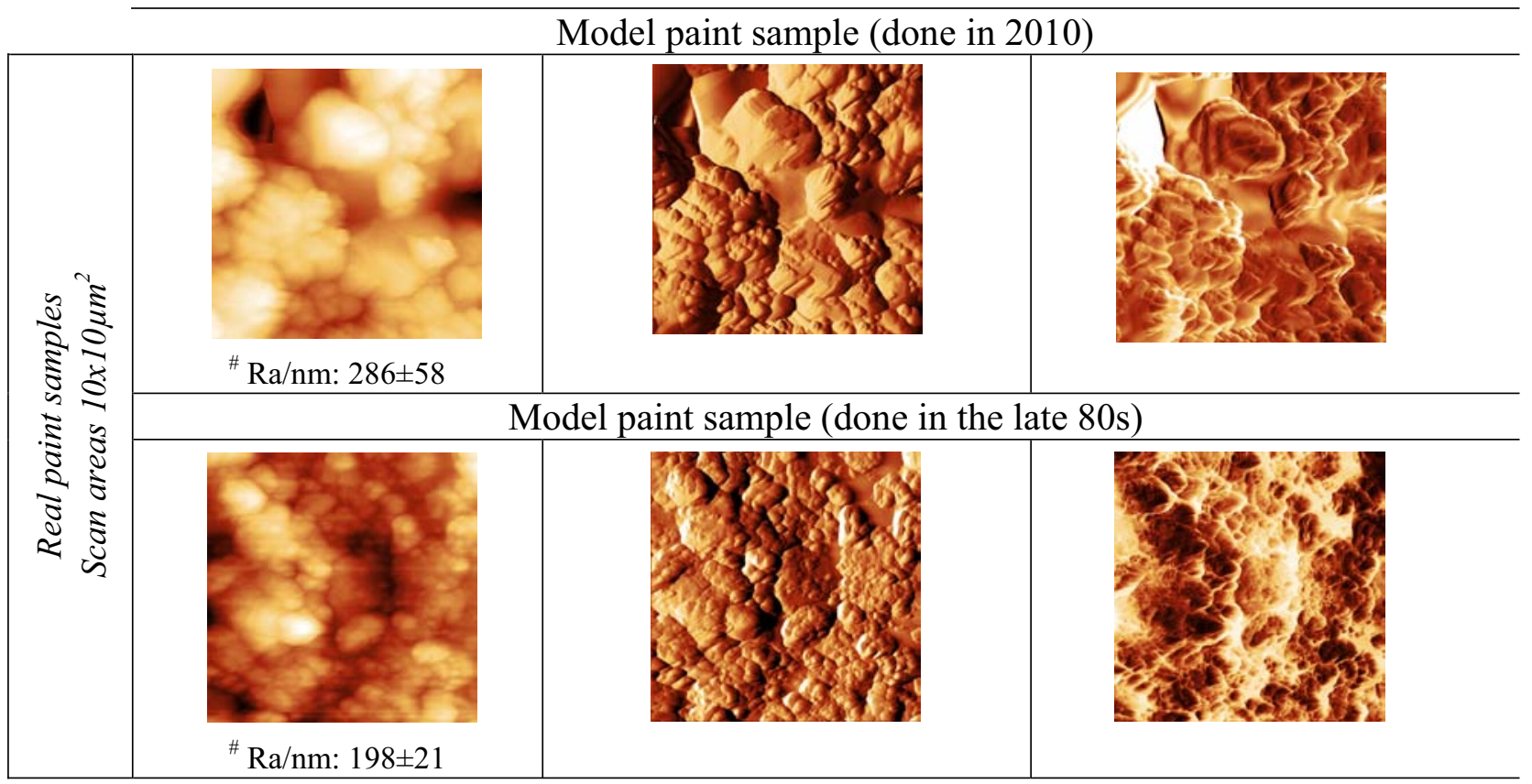

TABLE 2. AFM height, amplitude and phase images of the unaged and naturally aged samples

References

[1] M. H. de Sá; P. Eaton; J.L.Ferreira; M.J. Melo; A.M. Ramos. Ageing of vinyl emulsion paints an atomic forcemicroscopy study. DOI 10.1002/sia.3664

[2] A. I. Pereira acknowledges Fundação para a Ciência e Tecnologia (FCT/MCTES) for her PhD grant (SFRH/BD/39917/2007). 